Ricardo Palmier Teles ${ }^{(a)}$ Flavia Rocha Fonseca Teles ${ }^{(b)}$

(a) DMSc, Associate Member of the Staff; (b)DMSc, Post-doctoral Researcher - Department of Periodontology, The Forsyth Institute, Boston, MA, USA.
\$Paper presented at the "Oral Health Self-Care Products: Realities and Myths" international symposium, sponsored by the Brazilian Association for Oral Health Promotion (ABOPREV), September 25-27, 2008, São Paulo, SP, Brazil.

Corresponding author:

Ricardo Palmier Teles

Department of Periodontology,

The Forsyth Institute

140 The Fenway

Boston - MA - USA

ZIP: 02115

E-mail: rteles@forsyth.org

Received for publication on Nov 24, 2008 Accepted for publication on Dec 08, 2008

\section{Antimicrobial agents used in the control of periodontal biofilms: effective adjuncts to mechanical plaque control?s}

\begin{abstract}
The control of biofilm accumulation on teeth has been the cornerstone of periodontal disease prevention for decades. However, the widespread prevalence of gingivitis suggests the inefficiency of selfperformed mechanical plaque control in preventing gingival inflammation. This is particularly relevant in light of recent evidence suggesting that long standing gingivitis increases the risk of loss of attachment and that prevention of gingival inflammation might reduce the prevalence of mild to moderate periodontitis. Several antimicrobials have been tested as adjuncts to mechanical plaque control in order to improve the results obtained with oral home care. Recent studies, including meta-analyses, have indicated that home care products containing chemical antimicrobials can provide gingivitis reduction beyond what can be accomplished with brushing and flossing. Particularly, formulations containing chlorhexidine, mouthrinses containing essential oils and triclosan/copolymer dentifrices have well documented clinical antiplaque and antigingivitis effects. In vivo microbiological tests have demonstrated the ability of these antimicrobial agents to penetrate the biofilm mass and to kill bacteria growing within biofilms. In addition, chemical antimicrobials can reach difficult-to-clean areas such as interproximal surfaces and can also impact the growth of biofilms on soft tissue. These agents have a positive track record of safety and their use does not seem to increase the levels of resistant species. Further, no study has been able to establish a correlation between mouthrinses containing alcohol and oral cancer. In summary, the adjunct use of chemical plaque control should be recommended to subjects with well documented difficulties in achieving proper biofilm control using only mechanical means.
\end{abstract}

Descriptors: Dental plaque; Gingivitis; Oils, essential; Triclosan. 


\section{Introduction}

Since the 1960 s when Löe and coworkers ${ }^{1}$ established the unequivocal role of dental plaque as the etiological agent of gingivitis, mechanical plaque control has become the cornerstone of periodontal therapy. However, the almost ubiquitous prevalence of gingivitis would suggest that control of periodontal biofilms through mechanical means is inefficient. The difficulty in achieving an "ideal" mechanical plaque control has led scientists and clinicians to seek chemical antimicrobial agents that could help inhibit biofilm formation on tooth surfaces. The current review will concentrate on antimicrobial agents present in formulations of self-care oral hygiene products commercially available in the Brazilian market. The goal is to critically review products available to the Brazilian public regarding their antiplaque and antigingivitis effects. In addition, the effects of these chemical agents on the oral microbiota will be discussed. Important considerations such as the long-term safety of oral antimicrobial agents and the impact of control of gingivitis in the development and progression of more severe forms of periodontal diseases will also be addressed.

Current understanding of the pathogenesis of periodontal diseases indicates that the presence of gingivitis is a pre-requisite for the development of periodontitis. ${ }^{2}$ However, it is also well recognized that even long standing severe gingivitis will not necessarily lead to loss of attachment. ${ }^{3}$ These observations have led some authors to question the relevance of mild to moderate forms of gingivitis as a public health problem, and if efforts to control this disease at a populational level would be justifiable. ${ }^{4}$ Recent data from a 26-year longitudinal study of 565 Norwegian males indicated that sites that bled on probing on every examination (gingival index [GI] =2) had approximately $70 \%$ more attachment loss than non-inflamed sites (GI $=0$ at all visits). ${ }^{5}$ This study supports the pivotal role of gingivitis as a risk factor for attachment loss and emphasizes the chronic nature of periodontitis, requiring time to progress. Epidemiological data from a Swedish study following randomly selected individuals in different age groups (20-80 years of age) over a 30-year period (1973-2003) suggest that plaque control on a popu- lation level might reduce not only the prevalence of gingivitis but also the prevalence of moderate forms of periodontitis. ${ }^{6}$ Subjects were classified according to the severity of their periodontal disease into: 1) periodontal health; 2) gingivitis; 3) moderate periodontitis and 4) and 5) severe or advanced periodontitis. In all age groups the proportion of periodontally healthy subjects increased, while the prevalence of gingivitis and moderate periodontitis decreased. The percentage of individuals in category 4 also tended to decrease, while their number of remaining teeth increased over time. This 30-year cohort study demonstrates that strategies aiming at the control of gingivitis at a populational level could reduce the prevalence of mild to moderate forms of periodontitis.

\section{Limitations of mechanical plaque control}

Despite its essential role in the prevention of gingivitis and periodontitis, mechanical plaque control is not properly practiced by most individuals. A survey conducted in the United Kingdom concluded that an average of one-third of teeth in $72 \%$ of all dentate adults examined had visible plaque. ${ }^{7}$ Brushing techniques are particularly limited in their access to interproximal plaque of pre-molars and molars, and control of biofilm accumulation on these areas requires additional devices such as dental floss. ${ }^{8}$ Surveys conducted in developed countries reveal that the percentage of individuals who claim to use interproximal cleaning devices on a daily basis range from 11 to $51 \% .{ }^{9}$ A systematic review of the effectiveness of self-performed mechanical plaque removal in adults with gingivitis concluded that the quality of the mechanical plaque control was not sufficiently effective in reducing gingivitis. ${ }^{10}$ Taken together, these studies indicate that consistently effective brushing is uncommon, leaving room for improvement. Therefore, the adjunct use of antimicrobial agents might be beneficial for the adjunct control of supragingival biofilms.

An additional limitation of mechanical plaque control procedures is that they concentrate solely on the hard surfaces of the oral cavity. Although the non-shedding surfaces of the teeth provide an excellent surface for the establishment and growth of 
biofilms, they represent a relatively small percentage of the total area of the oral cavity $(21-23 \%) .{ }^{11}$ Recent studies have demonstrated that microorganisms involved in the etiology of gingivitis and periodontitis accumulate on several soft tissue surfaces of the mouth, which serve as a source of bacteria for the colonization of tooth surfaces. ${ }^{12}$ Chemical antiplaque agents present in mouthrinses or dentifrices could reach these soft tissue surfaces, improving the control of biofilm growth on these surfaces and delaying microbial accumulation on teeth. This mechanism was illustrated in a study that examined the rate of biofilm accumulation on teeth after a 3-week preparatory phase that included oral hygiene instructions and frequent professional cleanings. ${ }^{13} \mathrm{In}$ the last week of this preparatory phase, the experimental group rinsed and gargled twice a day with a $0.2 \%$ chlorhexidine digluconate $(\mathrm{CHX})$ solution and brushed their tongue with a $1 \% \mathrm{CHX}$ gel once a day. This intensive protocol of control of the soft tissue biofilm resulted in a lower mean plaque index (Turesky modified Quigley-Hein index [QHI ${ }^{14,15}$ ) at days 1, 2 and 4 of undisturbed plaque re-accumulation. Data from checkerboard DNA-DNA hybridization also revealed that the mean total DNA probe count was statistically significantly higher in the control group compared to the experimental group at days 2 and 4 of plaque re-growth. These findings suggest that the daily use of chemical antimicrobial agents that affect the soft tissue biofilms could retard plaque accumulation on tooth surfaces.

\section{Meta-analysis of antiplaque and antigingivitis agents}

A recently published meta-analysis of antiplaque and antigingivitis agents provided strong evidence in favor of the use of antimicrobial agents as adjuncts to mechanical plaque control. ${ }^{16} \mathrm{~A}$ total of 50 manuscripts including 70 active groups met the inclusion criteria and were analyzed. Of the dentifrices examined only formulations containing triclosan/copolymer demonstrated a clinically and statistically significant antiplaque effect. Fourteen of the 18 active groups using triclosan/copolymer had significant decreases in plaque accumulation. The author highlighted two mouthrinses with consistent anti- plaque effects: $0.12 \%$ CHX and essential oils-containing formulations (menthol [0.042\%], thymol [0.064\%], methyl salicylate $[0.060 \%]$, and eucalyptol $[0.092 \%])$. CHX resulted in statistically significant reduction in plaque in all studies reviewed. Only 1 active group out of 25 that used essential oils did not show statistically significant reductions in plaque. The results of studies employing GI to assess gingivitis were statistically and clinically significant for $0.12 \%$ CHX mouthrinses (5/6 active groups), dentifrices containing triclosan/copolymer (12/16 active groups) and mouthrinses with essential oils (3/8 active groups). Of the trials using MGI (Modified Gingival Index), 13/17 active groups demonstrated statistically significantly less gingivitis in the groups using essential oils compared to controls. Based on these results we will focus our review on studies examining the clinical and microbiological effects of triclosan/copolymer dentifrices and essential oil mouthrinses. CHX will not be reviewed extensively due to its well known side effects, which preclude its use as a long term adjunct to oral hygiene.

\section{Effects of essential oil mouthrinses on periodontal biofilms and gingivitis}

Essential oils have a broad antimicrobial spectrum, affecting Gram-positive and Gram-negative bacteria and yeasts. The efficacy of oral antiseptics is usually attributed to their bactericidal activity, but essential oils also work by interfering with bacterial colonization of the tooth surface. Essential oils stop bacteria from aggregating with Gram-positive pioneer species, slows bacterial multiplication, and extract endotoxins from Gram-negative pathogens. ${ }^{17}$ This can lead to a reduced bacterial load, slow plaque maturation, and decreased plaque mass and pathogenicity. The bactericidal mechanisms of essential oils involve the rupture of the cell wall and enzymatic inhibition. ${ }^{17}$

Bacteria growing in biofilms present a higher level of resistance to several antimicrobial agents compared to bacteria living in a planktonic state. ${ }^{18}$ For an oral antimicrobial agent to have meaningful in vivo efficacy, it is important that the active agent be capable of diffusing into the biofilm mass. The pen- 
etration of a mouthrinse containing essential oils in dental plaque was tested in vivo using fluorescent dyes that differentiate live and dead bacteria. ${ }^{19}$ Thirty minutes after a rinse with essential oils, 78.7\% of bacteria in plaque samples were dead compared to $27.9 \%$ following rinsing with a placebo. The results clearly demonstrated that the essential oils were capable of penetrating the plaque mass and exert their antimicrobial effect on bacteria growing within biofilms. These findings were confirmed by additional studies that demonstrated in vivo antimicrobial effects of mouthrinses containing essential oils on preexisting plaque. ${ }^{20,21,22}$ Fourteen days of twice-daily rinsing with an essential oils-containing mouthrinse resulted in statistically significant reductions compared to a placebo mouthrinse in supragingival levels of Veillonella sp. (52.3\%), Capnocytophaga sp. (74.1\%), Fusobacterium nucleatum $(81.5 \%)$ and total anaerobes $(88.5 \%) .{ }^{21}$ Moreover, this regimen also resulted in statistically significant reductions in subgingival plaque samples of target microorganisms ranging from 54.1 to $69.1 \%$, suggesting that rinsing with essential oils could also impact the subgingival microbiota. Using a similar design, the same group reported on the impact that rinsing for 14 days with an essential oil mouthrinse had on the subgingival levels of Porphyromonas gingivalis, Veillonella sp., F. nucleatum and total anaerobes. ${ }^{22}$ Thirty seven subjects with a minimum of 4 sites with probing depth of 4 to $7 \mathrm{~mm}$ were enrolled in the study. The results demonstrated statistically significant reductions in all target microorganisms in the essential oils group compared with the placebo group: P. gingivalis (64.5\%), Veillonella sp. $(56.6 \%)$, F. nucleatum $(76.6 \%)$ and total anaerobes $(74.9 \%)$. The authors suggested that the subgingival antimicrobial effect of the mouthrinse was mediated primarily by disruption of the contiguous supragingival biofilm. In addition, a regimen of twice daily rinsing with essential oils for 14 days can reduce the levels of total anaerobes, Gram-negative anaerobes and volatile sulphur compound-producing organisms in plaque and on the dorsum of the tongue up to 12 hours after the final rinse, indicating a certain level of substantivity. ${ }^{21}$

Several studies with a minimum of 6 months of follow-up using a double-blind, controlled, randomized design have reported on the adjunctive effects of essential oil mouthrinses on decreasing plaque accumulation and development of gingivitis. ${ }^{23-29}$ These reports have described an average reduction of $32.9 \%$ in plaque accumulation $(\mathrm{QHI})$, and of $22.1 \%$ in gingivitis (MGI) (Table 1 ) in the groups using essential oils. However, measures of total plaque reductions do not address the effects of these agents on specific areas of the oral cavity more prone to plaque accumulation and gingivitis such as the interproximal surfaces of posterior teeth. Some of the studies listed in Table 1 have addressed the efficacy of essential oils-containing mouthrinses in reducing plaque and gingivitis in interproximal areas. One study compared brushing plus the use of an essential oil mouthrinse (BEO) with brushing and flossing (BF) and brushing and rinsing with a placebo mouthrinse (B). ${ }^{28}$ After six months, the BEO and BF groups had statistically significantly lower mean interproximal MGI compared to the B group. The authors concluded that rinsing twice daily with an essential oils-containing mouthrinse was as efficient as daily flossing in reducing interproximal plaque and gingivitis. Another study examined the adjunctive benefit of essential oils in reducing plaque and gingivitis in subjects who brush and floss regularly. ${ }^{29}$ After six months the group that in addition to brushing and flossing used the essential oil mouthrinse had statistically and clinically significantly lower mean MGI and PI (Sillness-Löe Plaque

Table 1 - Antiplaque and antigingivitis effects of essential oil mouthrinses.

\begin{tabular}{|c|c|c|c|c|c|}
\hline Study & Year & N & Duration & $\begin{array}{c}\text { *Plaque } \\
\text { QHI }\end{array}$ & $\begin{array}{c}{ }^{*} \text { Gingivitis } \\
M G I\end{array}$ \\
\hline Gordon et al. ${ }^{23}$ & 1985 & 85 & 9 months & $19.5 \%$ & $23.9 \%$ \\
\hline DePaola et al. ${ }^{24}$ & 1989 & 107 & 6 months & $34.4 \%$ & $33.7 \%$ \\
\hline Overholser et al. ${ }^{25}$ & 1990 & 124 & 6 months & $36.1 \%$ & $35.9 \%$ \\
\hline Charles et al. ${ }^{26}$ & 2001 & 316 & 6 months & $56.1 \%$ & $22.9 \%$ \\
\hline Sharma et al. ${ }^{27}$ & 2002 & 301 & 6 months & $37.5 \%$ & $7.9 \%$ \\
\hline Bauroth et al. ${ }^{28}$ & 2003 & 314 & 6 months & $20.0 \%$ & $11.1 \%$ \\
\hline Sharma et al. ${ }^{29}$ & 2004 & 237 & 6 months & $51.9 \%$ & $21.0 \%$ \\
\hline
\end{tabular}

*Reduction in the Index. QHI - Turesky modified Quigley-Hein index. $M G I$ - Modified Gingival Index. 
Index) than individuals in the placebo group (21.0 and $51.9 \%$, respectively), suggesting that essential oils could be an effective adjunct to regular brushing and flossing.

In these studies, visual assessment of plaque removal and gingivitis reduction was performed to determine antiplaque and antigingivitis effects in interproximal areas. Due to the wide area of interproximal surfaces of premolars and molars, it is difficult to visually determine if plaque was completely removed from the interproximal area. Likewise, gingivitis might have been reduced in the vestibular and lingual/palatal portion of the interdental papilla but not in the col area. In order to demonstrate the antimicrobial efficacy of essential oil mouthrinses in the interproximal area, the effect of 11 days of twice daily rinse with an essential oils-containing mouthrinse on the interproximal levels of Streptococcus mutans was assessed. ${ }^{30}$ The results demonstrated a reduction of $75.4 \%$ in total recoverable $S$. mutans from interproximal spaces in the essential oils group. Another study evaluating the effects of essential oils in the total viable bacteria in the interproximal spaces demonstrated a statistically significant reduction of $43.8 \%$ in interproximal bacteria 5 minutes after a single 30 -second rinse. ${ }^{31}$

\section{Effects of Triclosan/copolymer dentifrices on periodontal biofilms and gingivitis}

Dentifrices containing $0.3 \%$ triclosan and 2\% polyvinyl methyl ether maleic acid copolymer (copolymer) have demonstrated significant antiplaque and antigingivitis properties. Triclosan is a broadspectrum antimicrobial agent, which acts on the bacterial cytoplasmic membrane. It prevents essential amino acid uptake at bacteriostatic concentrations, while at bactericidal concentrations it causes disorganization of the bacterial membrane leading to leakage of cellular contents. ${ }^{32}$ The copolymer acts by increasing the retention of triclosan on tooth and oral soft tissue surfaces. ${ }^{33}$ A greater uptake of triclosan to plaque and saliva was observed when copolymer was added to triclosan-containing dentifrices. ${ }^{34}$ Tests of the substantivity of toothpaste slurries demonstrated that dentifrices containing triclosan/copo- lymer reduced the proportions of vital bacteria in plaque for up to 24 hours. ${ }^{35}$ The effects of one-week, twice-daily use of triclosan/copolymer dentifrice on the levels of Veillonella sp., Fusobacteria sp., total anaerobes and hydrogen sulfide-producing bacteria were tested on samples of plaque, saliva and tongue scrapings 6 and 12 hours after the final brushing. ${ }^{36}$ Significant reductions (88 to $96 \%$ ) in total anaerobes were reported for the triclosan/copolymer group in the 3 sites at both time points compared with the control group. In plaque samples, Fusobacteria sp. decreased by 77 and $92 \%$ and Veillonella sp. decreased by 90 and $85 \%$ in the triclosan/copolymer group versus the control group 6 and 12 hours after brushing, respectively.

The effectiveness of dentifrices containing triclosan/copolymer in reducing plaque accumulation and gingivitis was examined in a systematic review. ${ }^{37}$ Only randomized clinical trials with at least 6 months of follow-up were included. A meta-analysis was performed on the results of 16 studies involving 1,150 control and 1,176 test subjects. The results demonstrated that the triclosan/copolymer toothpaste was capable of reducing plaque $(23 \%$ using the QHI and 49\% using the plaque severity index) and gingivitis (23\% using the GI and $49 \%$ using the gingivitis severity index). Table 2 presents the percentage reduction in plaque and gingivitis obtained in several studies examining the effectiveness of a triclosan/copolymer dentifrice. Most studies demonstrated statistically significant improvements in both parameters after 6 months of use of the product. ${ }^{38-50}$ In a few studies, however, differences between control and test groups were only significant at 3 months but not at 6 months (Table 3). ${ }^{44,51,52}$ The clinical effect of a triclosan/copolymer dentifrice on preexisting plaque and gingivitis has also been examined. ${ }^{45}$ After six months, the experimental group had a $34.9 \%$ reduction in the levels of preexisting plaque and a $25.7 \%$ reduction in gingivitis, compared with the placebo group.

In a 3-year study examining the clinical and microbiological changes associated with the combined use of a powered toothbrush and a triclosan/copolymer dentifrice, the authors could not demonstrate any clinical benefit of the use of the antimicrobial 
Table 2 - Antiplaque and antigingivitis effects of triclosan/ copolymer dentifrices.

\begin{tabular}{c|c|c|c|c|c|c|c}
\hline Study & Year & N & Duration & $\begin{array}{c}* \text { Plaque } \\
\text { QHI }\end{array}$ & $\begin{array}{c}\text { *Plaque } \\
\text { Severity }\end{array}$ & $\begin{array}{c}* \text { Gingivitis } \\
\text { LSI }\end{array}$ & $\begin{array}{c}* \text { Gingivitis } \\
\text { Severity }\end{array}$ \\
\hline Garcia-Godoy et al. ${ }^{38}$ & 1990 & 108 & 7 months & $58.9 \%$ & $97.7 \%$ & $30.2 \%$ & $87.7 \%$ \\
\hline Cubells et al. $^{39}$ & 1991 & 108 & 6 months & $24.9 \%$ & $50.8 \%$ & $19.7 \%$ & $57.5 \%$ \\
\hline Deasy et al. ${ }^{40}$ & 1991 & 121 & 6 months & $32.3 \%$ & $73.6 \%$ & $25.6 \%$ & $57.1 \%$ \\
\hline Denepitiya et al. ${ }^{41}$ & 1992 & 145 & 6 months & $18.4 \%$ & $29.2 \%$ & $31.5 \%$ & $57.1 \%$ \\
\hline Mankodi et al. ${ }^{46}$ & 1992 & 294 & 6 months & $11.9 \%$ & $19.3 \%$ & $19.7 \%$ & $73.6 \%$ \\
\hline Bolden et al. ${ }^{42}$ & 1992 & 306 & 6 months & $17.0 \%$ & $18.6 \%$ & $29.0 \%$ & $47.6 \%$ \\
\hline Triratana et al. ${ }^{48}$ & 1995 & 120 & 6 months & $32.9 \%$ & $46.0 \%$ & $18.8 \%$ & $38.3 \%$ \\
\hline Lindhe et al. ${ }^{49}$ & 1993 & 110 & 6 months & $31.2 \%$ & NR & $26.6 \%$ & NR \\
\hline Palomo et al. ${ }^{43}$ & 1994 & 98 & 6 months & $12.7 \%$ & $23.1 \%$ & $24.1 \%$ & $38.4 \%$ \\
\hline Kanchanakamol et al. ${ }^{44}$ & 1995 & 124 & 6 months & $12.1 \%$ & $16.3 \%$ & NR & NR \\
\hline Allen et al. ${ }^{50}$ & 2002 & 110 & 6 months & $29.9 \%$ & $59.2 \%$ & $21.4 \%$ & $69.2 \%$ \\
\hline Mankodi et al. ${ }^{47}$ & 2002 & 109 & 6 months & $18.7 \%$ & $60.5 \%$ & $22.2 \%$ & $85.1 \%$ \\
\hline Triratana et al. ${ }^{45}$ & 2002 & 124 & 6 months & $34.9 \%$ & $52.1 \%$ & $25.7 \%$ & $40.3 \%$ \\
\hline
\end{tabular}

*Reduction in the Index. QHI - Turesky modified Quigley-Hein index. LSI - Löe-Silness Gingival Index. Plaque Severity - Plaque Severity Index of Palomo and co-workers. Gingivitis Severity - Gingivitis Severity Index of Palomo and co-workers. Adapted from Panagakos et al.32 (2005). NR: Not reported.

Table 3 - Antiplaque and antigingivitis effects of triclosan/ copolymer dentifrices. The studies presented statistically significant differences only at 3 months.

\begin{tabular}{|c|c|c|c|c|c|}
\hline Study & Year & $\mathrm{N}$ & Duration & $\begin{array}{c}\text { *Plaque } \\
\text { PI }\end{array}$ & $\begin{array}{c}{ }^{*} \text { Gingivitis } \\
\text { BI }\end{array}$ \\
\hline Svatun et al. ${ }^{51}$ & 1993 & 94 & 7 months & $19.0 \%$ & $25.5 \%$ \\
\hline Kanchanakamol et al. ${ }^{44}$ & 1995 & 124 & 6 months & $7.2 \%$ & $25.0 \%$ \\
\hline Renvert, Birkhed 52 & 1995 & 60 & 6 months & $25.0 \%$ & $18.2 \%$ \\
\hline
\end{tabular}

*Reduction in the Index. PI - Silness-Löe Plaque Index. BI - Ainamo and Bay Bleeding Index. Adapted from Panagakos et al..$^{32}$ (2005).

toothpaste over the use of a manual toothbrush and a fluoride-containing dentifrice. ${ }^{53}$ Microbiological samples were collected at baseline and after 1,2 and 3 years and individually analyzed using the checkerboard DNA-DNA hybridization technique. Both groups resulted in similar reductions in mean total DNA probe count $\left(\times 10^{5}\right)$. The levels of the 40 species tested were reduced by both preventive regimens to similar levels. In this study both groups were part of comprehensive prevention programs involving recall visits every 6 months for reinforcement of homecare procedures and professional cleaning. In addition, subjects were provided with the appropriate toothbrush, dentifrice and interdental devices on every visit. A possible interpretation of the failure of this study in demonstrating an adjunctive antiplaque and antigingivitis effect of the triclosan/copolymer toothpaste is that when meticulous mechanical plaque control is performed, any additional benefit of an antimicrobial agent is minimal.

\section{Effects of Triclosan/copolymer dentifrices on periodontitis progression}

A 3-year double-blind, controlled, randomized trial examined the effects of twice daily use of triclosan/copolymer toothpaste on the prevention of attachment loss in adolescents (11-13 years old). ${ }^{54}$ The study demonstrated that for individuals with high mean pocket depths at baseline $(2.92$ $-4.19 \mathrm{~mm}$ ), the use of triclosan/copolymer resulted in lower mean attachment loss at the end of the study. The effects of triclosan/copolymer in the prevention of periodontitis in maintenance patients have also been examined. In one study the use of triclosan/copolymer dentifrice was capable of slow- 
ing the progression of periodontitis in maintenance subjects during the 3 years of the trial. ${ }^{55}$ The daily use of triclosan/copolymer toothpaste resulted in a lower frequency of deep periodontal pockets and a lower number of sites with additional attachment and bone loss by the end of the study. Conversely, a trial examining the 3 -year effect of the combined use of powered toothbrush and triclosan dentifrice in periodontal maintenance subjects failed to demonstrated superior clinical and microbial outcomes for the test group compared with a control group using manual toothbrush and a standard fluoride toothpaste. ${ }^{56}$ The discrepancy in the outcome of the two studies can be justified by differences in study design. In the former study no professional subgingival therapy was provided, while in the latter subgingival debridement was performed every 6 months. It seems that when meticulous subgingival mechanical debridement is performed, the benefits of the use of antimicrobial toothpaste cannot be demonstrated. In the absence of such supportive maintenance therapy, it is possible that the use of the triclosan/copolymer dentifrice resulted in a reduction in the levels of subgingival species, leading to additional clinical benefits. In fact, it has been demonstrated that careful supragingival plaque control with the adjunct use of triclosan/copolymer toothpaste can affect the subgingival microbiota. ${ }^{57}$

\section{Safety of oral antimicrobial agents}

The prolonged use of antimicrobial agents as adjuncts to mechanical plaque control raises two main concerns regarding safety: the development of resistant microorganisms and the risk of oral cancer associated with the alcohol content of mouthrinse formulations. Oral antiseptics affect a broad spectrum of microorganisms and have non-specific antimicrobial mechanisms, which affect a number of different targets in the microbial cell, inhibiting a variety of cellular processes. ${ }^{58}$ This is probably the main reason for the lack of development of bacterial resistance to antiseptics. Point mutations in the microorganism might affect one of the mechanisms of action of a given antiseptic, but rarely would result in resistance to all mechanisms. In fact, several studies have examined the long-term microbiological safety of dentifrices and mouthrinses containing antiplaque agents and none of them have reported the development of opportunistic infections, overgrowth of pathogenic bacteria or the development of resistant species. ${ }^{58}$

Concerns about the high content of alcohol in certain mouthwash formulations are justified based on the well established association between alcohol consumption and an elevated risk to develop oropharyngeal cancer. However, a review of studies that suggested a correlation between mouthrinses containing alcohol and oral cancer by the American Dental Association (ADA) and by the Food and Drug Administration (FDA) concluded that these studies presented several deficiencies. ${ }^{59}$ Among the problems detected in the studies there were the nonexclusion of subjects due to the consumption of alcoholic beverages or smoking and the inclusion of pharyngeal cancer in the analysis, while oral exposure to mouthrinses should not affect the pharynx. Two recent reviews on the topic concluded that there was no support in the literature for an association between mouthrinses containing alcohol and oropharyngeal cancer. ${ }^{60,61}$

\section{Concluding remarks}

- The adjunct use of essential oil mouthrinses and triclosan/copolymer dentifrices can result in additional reductions in plaque and gingivitis, particularly in hard-to-reach areas such as interproximal spaces.

- The use of chemical agents might help reduce the accumulation of biofilms on soft tissue surfaces of the oral cavity, potentially delaying plaque accumulation on teeth.

- Antimicrobial agents such as essential oils are capable of affecting bacteria growing in supragingival biofilms and disrupt preexisting plaque.

- The use of essential oil mouthrinses and dentifrices containing triclosan/copolymer might affect the subgingival microbiota through the disruption of the contiguous supragingival plaque.

- The use of a dentifrice containing triclosan/copolymer might prevent the progression of attachment loss in adolescent with a high risk of devel- 
oping "early periodontitis".

- The use of a dentifrice containing triclosan/copolymer might prevent further loss of attachment in patients with a history of periodontitis, particularly in the absence of a supportive periodontal therapy that includes subgingival debridement.

- Despite its limitations, meticulous mechanical supragingival plaque control is capable of reducing plaque accumulation and preventing gingivitis even without the adjunct use of antimicrobials.

- Well executed supra and subgingival mechanical

\section{References}

1. Loe H, Theilade E, Jensen SB. Experimental Gingivitis in man. J Periodontol. 1965;36:177-87.

2. Lang NP, Karring T. Proceedings of the $1^{\text {st }}$ European Workshop on Periodontology. Chicago: Quintessence Publishing; 1994.

3. Loe H, Anerud A, Boysen H, Smith M. The natural history of periodontal disease in man. Study design and baseline data. J Periodontal Res. 1978;13(6):550-62.

4. Sheiham A. Is the chemical prevention of gingivitis necessary to prevent severe periodontitis? Periodontol 2000. 1997;15:1524.

5. Schatzle M, Loe H, Burgin W, Anerud A, Boysen H, Lang NP. Clinical course of chronic periodontitis. I. Role of gingivitis. J Clin Periodontol. 2003;30(10):887-901.

6. Hugoson A, Sjodin B, Norderyd O. Trends over 30 years, 1973-2003, in the prevalence and severity of periodontal disease. J Clin Periodontol. 2008;35(5):405-14.

7. Morris AJ, Steele J, White DA. The oral cleanliness and periodontal health of UK adults in 1998. Br Dent J. 2001;191(4):186-92.

8. Axelsson P, Albandar JM, Rams TE. Prevention and control of periodontal diseases in developing and industrialized nations. Periodontol 2000. 2002;29:235-46.

9. Bakdash B. Current patterns of oral hygiene product use and practices. Periodontol 2000. 1995;8:11-4.

10. van der Weijden GA, Hioe KP. A systematic review of the effectiveness of self-performed mechanical plaque removal in adults with gingivitis using a manual toothbrush. J Clin Periodontol. 2005;32(S):6214-28.

11. Kerr WJ, Kelly J, Geddes DA. The areas of various surfaces in the human mouth from nine years to adulthood. J Dent Res. 1991;70(12):1528-30.

12. Socransky SS, Haffajee AD. Periodontal microbial ecology. Periodontol 2000. 2005;38:135-87.

13. Sekino S, Ramberg P, Uzel NG, Socransky S, Lindhe J. The effect of a chlorhexidine regimen on de novo plaque formation. J Clin Periodontol. 2004;31(8):609-14. plaque control is capable of preventing further loss of attachment in subjects under periodontal maintenance even without the adjunct use of antimicrobials.

- The long term use of oral antimicrobials does not seem to lead to undesirable microbiological side effects such as the development of resistant species.

- The use of mouthrinses containing alcohol does not seem to increase the risk of oral cancer.

14. Quigley GA, Hein JW. Comparative cleansing efficiency of manual and power brushing. J Am Dent Assoc. 1962;65:269.

15. Turesky S, Gilmore ND, Glickman I. Reduced plaque formation by the chloromethyl analogue of victamine C. J Periodontol. $1970 ; 41(1): 41-3$.

16. Gunsolley JC. A meta-analysis of six-month studies of antiplaque and antigingivitis agents. J Am Dent Assoc. 2006;137(12):1649-57.

17. Fine DH, Furgang D, Lieb R, Korik I, Vincent JW, Barnett ML. Effects of sublethal exposure to an antiseptic mouthrinse on representative plaque bacteria. J Clin Periodontol. 1996;23(5):444-51.

18. Marsh PD. Dental plaque: biological significance of a biofilm and community life-style. J Clin Periodontol. 2005;32 Suppl 6:7-15.

19. Pan P, Barnett ML, Coelho J, Brogdon C, Finnegan MB. Determination of the in situ bactericidal activity of an essential oil mouthrinse using a vital stain method. J Clin Periodontol. 2000;27(4):256-61.

20. Fine DH, Markowitz K, Furgang D, Goldsmith D, Charles $\mathrm{CH}$, Lisante TA et al. Effect of an essential oil-containing antimicrobial mouthrinse on specific plaque bacteria in vivo. J Clin Periodontol. 2007;34(8):652-7.

21. Fine DH, Furgang D, Sinatra K, Charles C, McGuire A, Kumar LD. In vivo antimicrobial effectiveness of an essential oil-containing mouth rinse $12 \mathrm{~h}$ after a single use and 14 days' use. J Clin Periodontol. 2005;32(4):335-40.

22. Fine DH, Markowitz K, Furgang D, Goldsmith D, Ricci-Nittel $\mathrm{D}$, Charles $\mathrm{CH}$ et al. Effect of rinsing with an essential oilcontaining mouthrinse on subgingival periodontopathogens. J Periodontol. 2007;78(10):1935-42.

23. Gordon JM, Lamster IB, Seiger MC. Efficacy of Listerine antiseptic in inhibiting the development of plaque and gingivitis. J Clin Periodontol. 1985;12(8):697-704.

24. DePaola LG, Overholser CD, Meiller TF, Minah GE, Niehaus $\mathrm{C}$. Chemotherapeutic inhibition of supragingival den- 
tal plaque and gingivitis development. J Clin Periodontol. 1989;16(5):311-5.

25. Overholser CD, Meiller TF, DePaola LG, Minah GE, Niehaus C. Comparative effects of 2 chemotherapeutic mouthrinses on the development of supragingival dental plaque and gingivitis. J Clin Periodontol. 1990;17(8):575-9.

26. Charles CH, Sharma NC, Galustians HJ, Qaqish J, McGuire JA, Vincent JW. Comparative efficacy of an antiseptic mouthrinse and an antiplaque/antigingivitis dentifrice. A six-month clinical trial. J Am Dent Assoc. 2001;132(5):670-5.

27. Sharma NC, Charles CH, Qaqish JG, Galustians HJ, Zhao Q, Kumar LD. Comparative effectiveness of an essential oil mouthrinse and dental floss in controlling interproximal gingivitis and plaque. Am J Dent. 2002;15(6):351-5.

28. Bauroth K, Charles CH, Mankodi SM, Simmons K, Zhao Q, Kumar LD. The efficacy of an essential oil antiseptic mouthrinse vs. dental floss in controlling interproximal gingivitis: a comparative study. J Am Dent Assoc. 2003;134(3):359-65.

29. Sharma N, Charles CH, Lynch MC, Qaqish J, McGuire JA, Galustians JG et al. Adjunctive benefit of an essential oilcontaining mouthrinse in reducing plaque and gingivitis in patients who brush and floss regularly: a six-month study. J Am Dent Assoc. 2004;135(4):496-504.

30. Fine DH, Furgang D, Barnett ML, Drew C, Steinberg L, Charles $\mathrm{CH}$ et al. Effect of an essential oil-containing antiseptic mouthrinse on plaque and salivary Streptococcus mutans levels. J Clin Periodontol. 2000;27(3):157-61.

31. Charles CH, Pan PC, Sturdivant L, Vincent JW. In vivo antimicrobial activity of an essential oil-containing mouthrinse on interproximal plaque bacteria. J Clin Dent. 2000;11(4):94-7.

32. Panagakos FS, Volpe AR, Petrone ME, DeVizio W, Davies RM, Proskin HM. Advanced oral antibacterial/anti-inflammatory technology: A comprehensive review of the clinical benefits of a triclosan/copolymer/fluoride dentifrice. J Clin Dent. 2005;16(S):1-19.

33. Afflitto J, Fakhry-Smith S, Gaffar A. Salivary and plaque triclosan levels after brushing with a $0.3 \%$ triclosan/copolymer/NaF dentifrice. Am J Dent. 1989;2(S):207-10.

34. Gaffar A, Nabi N, Kashuba B, Williams M, Herles S, Olsen $S$ et al. Antiplaque effects of dentifrices containing triclosan/ copolymer/NaF system versus triclosan dentifrices without the copolymer. Am J Dent. 1990;3(S):7-14.

35. Arweiler NB, Auschill TM, Reich E, Netuschil L. Substantivity of toothpaste slurries and their effect on reestablishment of the dental biofilm. J Clin Periodontol. 2002;29(7):615-21.

36. Fine DH, Furgang D, Markowitz K, Sreenivasan PK, Klimpel K, De Vizio W. The antimicrobial effect of a triclosan/copolymer dentifrice on oral microorganisms in vivo. J Am Dent Assoc. 2006;137(10):1406-13.

37. Davies RM, Ellwood RP, Davies GM. The effectiveness of a toothpaste containing triclosan and polyvinyl-methyl ether maleic acid copolymer in improving plaque control and gingival health: a systematic review. J Clin Periodontol. 2004;31(12):1029-33.

38. Garcia-Godoy F, Garcia-Godoy F, DeVizio W, Volpe AR, Ferlauto RJ, Miller JM. Effect of a triclosan/copolymer/fluoride dentifrice on plaque formation and gingivitis: a 7-month clinical study. Am J Dent. 1990;3 Spec No:S15-S26.

39. Cubells AB, Dalmau LB, Petrone ME, Chaknis P, Volpe AR. The effect of A Triclosan/copolymer/fluoride dentifrice on plaque formation and gingivitis: a six-month clinical study. J Clin Dent. 1991;2(3):63-9.

40. Deasy MJ, Singh SM, Rustogi KN, Petrone DM, Battista G, Petrone ME et al. Effect of a dentifrice containing triclosan and a copolymer on plaque formation and gingivitis. Clin Prev Dent. 1991;13(6):12-9.

41. Denepitiya JL, Fine D, Singh S, DeVizio W, Volpe AR, Person P. Effect upon plaque formation and gingivitis of a triclosan/ copolymer/fluoride dentifrice: a 6-month clinical study. Am J Dent. 1992;5(6):307-11.

42. Bolden TE, Zambon JJ, Sowinski J, Ayad F, McCool JJ, Volpe AR et al. The clinical effect of a dentifrice containing triclosan and a copolymer in a sodium fluoride/silica base on plaque formation and gingivitis: a six-month clinical study. J Clin Dent. 1992;3(4):125-31.

43. Palomo F, Wantland L, Sanchez A, Volpe AR, McCool J, DeVizio W. The effect of three commercially available dentifrices containing triclosan on supragingival plaque formation and gingivitis: a six month clinical study. Int Dent J. 1994;44(S):75-81.

44. Kanchanakamol U, Umpriwan R, Jotikasthira N, Srisilapanan P, Tuongratanaphan S, Sholitkul W et al. Reduction of plaque formation and gingivitis by a dentifrice containing triclosan and copolymer. J Periodontol. 1995;66(2):109-12.

45. Triratana T, Rustogi KN, Volpe AR, DeVizio W, Petrone M, Giniger M. Clinical effect of a new liquid dentifrice containing triclosan/copolymer on existing plaque and gingivitis. J Am Dent Assoc. 2002;133(2):219-25.

46. Mankodi S, Walker C, Conforti N, DeVizio W, McCool JJ, Volpe AR. Clinical effect of a triclosan-containing dentifrice on plaque and gingivitis: a six-month study. Clin Prev Dent. 1992;14(6):4-10.

47. Mankodi S, Lopez M, Smith I, Petrone DM, Petrone ME, Chaknis $\mathrm{P}$ et al. Comparison of two dentifrices with respect to efficacy for the control of plaque and gingivitis, and with respect to extrinsic tooth staining: a six-month clinical study on adults. J Clin Dent. 2002;13(6):228-33.

48. Triratana T, Kraivaphan P, Amornchat C, Rustogi K, Petrone MP, Volpe AR. Effect of a triclosan/copolymer pre-brush mouthrinse on established plaque formation and gingivitis: a six-month clinical study in Thailand. J Clin Dent. 1995;6(2):142-7.

49. Lindhe J, Rosling B, Socransky SS, Volpe AR. The effect of a triclosan-containing dentifrice on established plaque and gingivitis. J Clin Periodontol. 1993;20(5):327-34. 
50. Allen DR, Battista GW, Petrone DM, Petrone ME, Chaknis P, DeVizio W et al. The clinical efficacy of Colgate Total Plus Whitening Toothpaste containing a special grade of silica and Colgate Total Fresh Stripe Toothpaste in the control of plaque and gingivitis: a six-month clinical study. J Clin Dent. 2002;13(2):59-64.

51. Svatun B, Sadxton CA, Huntington E, Cummins D. The effects of three silica dentifrices containing Triclosan on supragingival plaque and calculus formation and on gingivitis. Int Dent J. 1993;43(4 Suppl 1):441-52.

52. Renvert S, Birkhed D. Comparison between 3 triclosan dentifrices on plaque, gingivitis and salivary microflora. J Clin Periodontol. 1995;22(1):63-70.

53. Bogren A, Teles RP, Torresyap G, Haffajee AD, Socransky SS, Wennstrom JL. Clinical and microbiologic changes associated with the combined use of a powered toothbrush and a triclosan/copolymer dentifrice: a 3-year prospective study. J Periodontol. 2007;78(9):1708-17.

54. Ellwood RP, Worthington HV, Blinkhorn AS, Volpe AR, Davies RM. Effect of a triclosan/copolymer dentifrice on the incidence of periodontal attachment loss in adolescents. J Clin Periodontol. 1998;25(5):363-7.
55. Rosling B, Wannfors B, Volpe AR, Furuichi Y, Ramberg P, Lindhe J. The use of a triclosan/copolymer dentifrice may retard the progression of periodontitis. J Clin Periodontol. 1997;24(12):873-80.

56. Bogren A, Teles RP, Torresyap G, Haffajee AD, Socransky SS, Jonsson $\mathrm{K}$ et al. Long-term effect of the combined use of powered toothbrush and triclosan dentifrice in periodontal maintenance patients. J Clin Periodontol. 2008;35(2):15764.

57. Rosling B, Dahlen G, Volpe A, Furuichi Y, Ramberg P, Lindhe J. Effect of triclosan on the subgingival microbiota of periodontitis-susceptible subjects. J Clin Periodontol. 1997;24(12):881-7.

58. Sreenivasan P, Gaffar A. Antiplaque biocides and bacterial resistance: a review. J Clin Periodontol. 2002;29(11):965-74.

59. Claffey N. Essential oil mouthwashes: a key component in oral health management. J Clin Periodontol. 2003;30(S):522-4.

60. Cole P, Rodu B, Mathisen A. Alcohol-containing mouthwash and oropharyngeal cancer: a review of the epidemiology. J Am Dent Assoc. 2003;134(8):1079-87.

61. Elmore JG, Horwitz RI. Oral cancer and mouthwash use: evaluation of the epidemiologic evidence. Otolaryngol Head Neck Surg. 1995;113(3):253-61. 